\title{
Pharmacologically induced impairment of neurovascular coupling responses alters gait coordination in mice
}

\author{
Stefano Tarantini • Andriy Yabluchanksiy • Gábor A. Fülöp • Peter Hertelendy • \\ M. Noa Valcarcel-Ares • Tamas Kiss • Jonathan M. Bagwell • Daniel O'Connor • \\ Eszter Farkas • Farzaneh Sorond • Anna Csiszar • Zoltan Ungvari 1 (D)
}

Received: 3 October 2017 / Accepted: 1 December 2017 /Published online: 14 December 2017

(C) American Aging Association 2017

\begin{abstract}
There is correlative evidence that impaired cerebral blood flow (CBF) regulation, in addition to promoting cognitive impairment, is also associated with alterations in gait and development of falls in elderly people. $\mathrm{CBF}$ is adjusted to neuronal activity via neurovascular coupling (NVC) and this mechanism becomes progressively impaired with age. To establish a direct cause-andeffect relationship between impaired NVC and gait abnormalities, we induced neurovascular uncoupling pharmacologically in young C57BL/6 mice by inhibiting the synthesis of vasodilator mediators involved in NVC. Treatment of mice with the epoxygenase inhibitor MSPPOH, the NO synthase inhibitor L-NAME, and the COX inhibitor indomethacin significantly decreased NVC mimicking the aging phenotype. Pharmacologically induced neurovascular uncoupling significantly decreased
\end{abstract}

Stefano Tarantini, Andriy Yabluchanksiy, Gábor A. Fülöp and Peter Hertelendy contributed equally to this work.

S. Tarantini · A. Yabluchanksiy · G. A. Fülöp •

P. Hertelendy · M. N. Valcarcel-Ares • T. Kiss •

J. M. Bagwell $\cdot$ D. O'Connor · A. Csiszar $\cdot$ Z. Ungvari $(\bowtie)$

Reynolds Oklahoma Center on Aging, Department of Geriatric Medicine, University of Oklahoma Health Sciences Center,

Oklahoma City, OK, USA

e-mail: zoltan-ungvari@ouhsc.edu

S. Tarantini · A. Yabluchanksiy · G. A. Fülöp •

P. Hertelendy · A. Csiszar · Z. Ungvari

Translational Geroscience Laboratory, Department of Geriatric

Medicine, University of Oklahoma Health Sciences Center,

Oklahoma City, OK, USA the dynamic gait parameter duty cycle, altered footfall patterns, and significantly increased phase dispersion, indicating impaired interlimb coordination. Impaired NVC also tended to increase gait variability. Thus, selective experimental disruption of NVC causes subclinical gait abnormalities, supporting the importance of $\mathrm{CBF}$ in both cognitive function and gait regulation.

Keywords Neurovascular coupling · Gait · Catwalk · Neurovascular uncoupling

\section{Introduction}

Vascular contributions to cognitive impairment and dementia (VCID) in aging have garnered much interest in

\footnotetext{
G. A. Fülöp

Division of Clinical Physiology, Faculty of Medicine, University of Debrecen, Debrecen, Hungary

J. M. Bagwell

Department of Veterinary Pathobiology, Oklahoma State

University, Stillwater, OK, USA

E. Farkas · A. Csiszar · Z. Ungvari

Department of Medical Physics and Informatics, Faculty of

Medicine and Faculty of Science and Informatics, University of Szeged, Szeged, Hungary

F. Sorond

Department of Neurology, Northwestern University, Chicago, IL, USA
} 
the past decade (Corriveau et al. 2016; Csiszar et al. 2017; Gorelick et al. 2011; Snyder et al. 2015; Toth et al. 2017; Tucsek et al. 2017). There are numerous agerelated vascular pathologies underlying VCID. It has become evident that in addition to pathologies affecting the larger cerebral arteries (e.g., atherosclerosis promoting cerebral ischemia) and cerebral microvessels (including arteriosclerosis, blood-brain barrier disruption, microvascular rarefaction, microvascular amyloid deposition, microhemorrhages) (Tucsek et al. 2014a, b, 2017; Ungvari et al. 2017b), functional impairment of cerebral microvessels resulting in dysregulation of cerebral blood flow (CBF) also has a critical role in the agerelated decline of brain function (Csiszar et al. 2017; Tarantini et al. 2016; Toth et al. 2017; Zlokovic 2011).

There is growing evidence that functional impairment of the neurovascular unit develops early during aging before manifestation of other pathologies (Balbi et al. 2015), and that it importantly contributes to age-related impairment of brain function (Tarantini et al. 2016; Toth et al. 2017). The energetic demand of active neurons is high and their proper function depends on constant, tightly controlled delivery of oxygen and nutrients via the microcirculatory network. With increased neuronal activity there is a requirement for rapid compensatory increases in oxygen and glucose delivery to the active brain regions. This "functional hyperemia" is elicited through the process of neurovascular coupling, a feed-forward control mechanism orchestrated by cells of the neurovascular unit, which adjusts $\mathrm{CBF}$, via regulating microvascular resistance, to the energy requirements of activated neurons (Attwell et al. 2010; Tarantini et al. 2016; Toth et al. 2017). Functional hyperemia is not only responsible for increased delivery of oxygen and nutrients, it also enables effective washout of noxious substances, ensuring an optimal humoral microenvironment in the cerebral tissue. The cellular mechanisms underlying neurovascular coupling include synthesis of nitric oxide (NO) by activated neurons and/or endothelial of nitric oxide (NO) and astrocytic production of vasodilator eicosanoid metabolites, including epoxygenase-derived epoxyeicosatrienoic acids (EETs) and cyclooxygenase-derived prostaglandins(Chen et al. 2014; Ma et al. 1996; Peng et al. 2002; Stobart et al. 2013; Takano et al. 2006; Tarantini et al. 2015, 2016, 2017; Toth et al. 2014, 2015a, b, 2017; Tucsek et al. 2014b; Ungvari et al. 2017a; Zonta et al. 2003). There is strong evidence that aging is associated with impairment of functional hyperemia (termed "neurovascular uncoupling") due to dysregulated release and/or increased degradation of NO, EETs, and prostaglandins (Stefanova et al. 2013; Tarantini et al. 2016; Topcuoglu et al. 2009; Toth et al. 2014). Neurovascular uncoupling is also manifested in pathophysiological conditions associated with accelerated cerebromicrovascular aging and cognitive impairment, including hypertension (Kazama et al. 2004), post-irradiation cognitive decline (Ungvari et al. 2017a), and obesity (Tucsek et al. 2014) both in human and laboratory models. Neurovascular dysfunction is also an early alteration in animal models of Alzheimer's disease (Girouard and Iadecola 2006; Lourenco et al. 2017; Tarantini et al. 2017).

Impaired delivery of nutrients and oxygen due to neurovascular dysfunction is expected to adversely affect neuronal function. Indeed, impaired neurovascular coupling responses in the elderly were shown to associate with impaired higher cognitive function (Sorond et al. 2013). Experimental studies in mouse models with pharmacological inhibition of the synthesis of NO, EETs, and prostaglandins confirm that a causal link exists between neurovascular dysfunction and cognitive impairment. In particular, pharmacologically induced neurovascular coupling was shown to result in impairment of spatial and recognition memory, mimicking the aging phenotype (Tarantini et al. 2015).

Human studies suggested that age-related neurovascular uncoupling also associates with gait abnormalities (Sorond et al. 2011). The significance of this observation is threefold. First, gait is no longer considered merely an automated motor activity (Atkinson et al. 2007). There is strong evidence that gait coordination requires normal executive function. Importantly, cognitive impairment and gait abnormalities frequently coexist in the elderly and in patients with neurodegenerative disease. In fact, gait disorders could manifest long before cognitive impairment is clinically evident (Mielke et al. 2013; Verghese et al. 2002). It is predicted that shared mechanisms, including microvascular pathologies that similarly affect brain regions involved in cognition and motor coordination, contribute to both cognitive impairment and gait dysfunction. Based on the complex interaction between brain regions involved in cognition and gait coordination in recent years, the concept has emerged that gait abnormalities may predict cognitive decline (Belghali et al. 2017; Callisaya et al. 2017; Fitzpatrick et al. 2007; Holtzer et al. 2006; Mielke et al. 2013; Verghese et al. 2007). Although there is growing evidence that neurovascular uncoupling contributes to cognitive decline, the role of neurovascular health in gait abnormalities 
remains elusive. Second, gait dysfunction in older adults is a major cause of functional impairment, contributes to falls, and predicts increased risk of institutionalization and mortality (Mignardot et al. 2014; Nakamura et al. 1996; Sorond et al. 2010; Verghese et al. 2009). Third, gait abnormalities were shown to be associated with survival in older adults (Studenski et al. 2011). Identification of potentially preventable causes of gait dysfunction has great relevance for maintaining functional independence in late life, preventing falls and possibly preserving cognition before impairment ensues. However, because senile gait disorders are likely multifactorial, in previous studies, it has been challenging to establish the mechanistic link between neurovascular dysfunction and gait abnormalities.

The present study was designed to test the hypothesis that neurovascular dysfunction per se results in alterations of gait coordination. To achieve this goal, neurovascular dysfunction was induced experimentally in healthy young control mice by treatment with specific pharmacological inhibitors of synthesis of nitric oxide, epoxyeicosatrienoic acids, and prostaglandins followed by assessment of gait coordination. To verify treatment efficiency, whisker stimulation-induced neurovascular coupling responses were measured by assessing CBF in the somatosensory whisker barrel cortex using a laser Doppler flow probe. To assess the effects of experimentally induced neurovascular uncoupling in laboratory mice, we analyzed gait parameters that have direct translational relevance (e.g., gait speed, swing speed, cadence, stride length, stride time, base of support) and also developed the methods to analyze stride time and stride length variability, which are considered sensitive indices of human gait abnormalities.

\section{Methods}

All the performed procedures were approved by the Institutional Animal Care and Use Committee of the University of Oklahoma Health Sciences Center.

\section{Animals and pharmacological treatments}

To study the effects of neurovascular uncoupling, young male C57BL/ $6 \mathrm{~J}$ mice ( 5 months old, $n=10$ per group) were obtained from the Jackson Laboratories (Bar Harbor, ME). Mice were kept under specific pathogen-free barrier conditions in the Rodent Barrier Facility at University of Oklahoma Health Sciences Center under a controlled photoperiod (12 h light; $12 \mathrm{~h}$ dark). The animals were divided into two groups: (1) mice with experimentally induced neurovascular dysfunction were administered pharmacological inhibitors to disrupt production of mediators involved in functional hyperemia (nitric oxide, epoxyeicosatrienoic acids, and prostaglandins) (Tarantini et al. 2015); and (2) sham controls receiving vehicle treatment. To inhibit the production of EETs, mice were treated with $N$-(methylsulfonyl)2-(2-propynyloxy)-benzenehexanamide (MS-PPOH), a specific inhibitor of EET-producing epoxidases (BrandSchieber et al. 2000), as described (Tarantini et al. 2015). Alzet osmotic minipumps ( 7 days, $1 \mu \mathrm{l} / \mathrm{h}$, $200 \mu$ total volume, Cat No.: 2001; Durect Corp., Cupertino, CA) were filled with MS-PPOH $(20 \mathrm{mg} / \mathrm{kg} /$ day, dissolved in DMSO and diluted to final concentration with $45 \%$ cyclodextrin (Brand-Schieber et al. 2000)) and implanted subcutaneously. Sham operated control animals received vehicle. To inhibit synthesis of vasodilator $\mathrm{NO}$, mice were treated with the $\mathrm{NO}$ synthase inhibitor $\mathrm{N}(\mathrm{G})$-Nitro-L-arginine methyl ester (LNAME, $100 \mathrm{mg} / \mathrm{kg} /$ day; in drinking water) (Wakisaka et al. 2010). Indomethacin (INDO; $7.5 \mathrm{mg} / \mathrm{kg} /$ day, p.o.), a non-selective inhibitor of cyclooxygenases, was used to disrupt NVC responses by cyxlooxygenase-derived vasodilator arachidonic acid metabolites. Indomethacin was dissolved in ethanol and diluted in 5\% $(w / v)$ sodium bicarbonate solution. The maximum administered daily volume of ethanol was $3 \mu \mathrm{l}$ per animal. The treatments were continued throughout the entire experimental period ( 7 days). Blood pressure of the animals was recorded before the treatment, and on day 3 of the treatment period, by the tail cuff method, as previously described (Toth et al. 2013).

\section{Analysis of gait function}

To determine the impact of impaired NVC responses on gait coordination, we tested the experimental groups of mice using an automated computer-assisted method (CatWalk; Noldus Information Technology Inc.) before and 3 days after the initiation of the pharmacological treatment, when the animals completely recovered from surgery. Using the CatWalk system, the detection of paw print size and paw placement patterns during volunteer running on an illuminated glass walkway by a camera placed under the glass surface provides an automated analysis of gait function and the spatial and temporal aspects of interlimb coordination (Tarantini et al. 2015; 
Ungvari et al. 2017a). Briefly, animals were trained to cross the walkway and then, in a dark and silent room ( $<20$ lx of illumination), animals were tested in 20 consecutive runs (to obtain $>200$ steps per animal). Data were averaged across $\sim 20$ runs in which the animal maintained a constant speed across the walkway. After manual identification and labeling of each footprint, the variability of the data has been assessed using quartile dispersion. We adopted a common outlier definition, labeling points more than 1.5 interquartile ranges away from the sample median as extreme values. After variability analyses, spatial and temporal gait parameters were calculated.

Base of support is the average width between either the front paws or the hind paws. Swing speed is the speed $(\mathrm{cm} / \mathrm{s})$ of the paw during swing. Stride length is the distance (in $\mathrm{cm}$ ) between successive placements of the same paw. The regularity index (\%) is a fractional measure of interpaw coordination, which expresses the number of normal step sequence patterns relative to the total number of paw placements. The formula of regularity index is as follows: (normal step sequence patterns) $\times 4 /$ (total number of paw placements $) \times 100(\%)$. In healthy, fully coordinated animals, its value is close to $100 \%$. Phase dispersion provides a quantitative metric of interpaw coordination. Phase dispersion characterizes the placement of two paws ("target" and "anchor") during the cycle of consecutive initial contacts with an anchor paw. In a step cycle, base of support gives the distance between the mass-midpoints of the fore prints at maximal contact. The results are averaged and expressed in centimeter. Duty cycle (\%) is expressed as stand time as a percentage of step cycle (Duty Cycle $=$ Stand time / (Stand time + Swing time $\times 100 \%)$ ).

Terminal dual stance (in seconds) is a measure of simultaneous contralateral support, calculated as the duration of ground contact for both hind paws simultaneously; it is the second step in a step cycle of a hind paw that the contralateral hind paw also makes contact with the glass plate. Cadence is the rate at which a mouse walks, expressed in steps per second.

Investigating gait variability (Beauchet et al. 2017; Decker et al. 2016), the stride-to-stride fluctuations in gait parameters offers a sensitive, novel method of quantifying subtle changes in locomotion in mice. Step time and step length variability were analyzed by computing the median absolute deviation (MAD) for datasets that contained $>200$ steps for each animal, obtained in consecutive runs at similar speeds. MAD is a robust measure of statistical dispersion, which is more resilient to outliers in a data set than the standard deviation.

Measurement of neurovascular coupling responses and somatosensory-evoked field potentials

After behavioral testing, mice in each group were anesthetized ( $\alpha$-chloralose $(50 \mathrm{mg} / \mathrm{kg}$, i.p.)/urethane $(750 \mathrm{mg} / \mathrm{kg}$, i.p.), endotracheally intubated, and ventilated (MousVent G500; Kent Scientific Co, Torrington, CT). A thermostatic heating pad (Kent Scientific Co, Torrington, CT) was used to maintain rectal temperature at $37{ }^{\circ} \mathrm{C}$ (Toth et al. 2014). End-tidal $\mathrm{CO}_{2}$ (including dead space) was controlled between 3.2 and $3.7 \%$ to keep blood gas values within the physiological range as described (Tarantini et al. 2015; Toth et al. 2014; Ungvari et al. 2017a). The right femoral artery was cannulated for arterial blood pressure measurement (Living Systems Instrumentations, Burlington, VT) (Toth et al. 2014). The blood pressure was within the physiological range throughout the experiments $(90-110 \mathrm{mmHg})$. Mice were immobilized and placed on a stereotaxic frame (Leica Microsystems Inc., Buffalo Grove, IL) as the scalp and periosteum were pulled aside. The animals were equipped with an open cranial window as described (Tarantini et al. 2015; Toth et al. 2014) and a glassinsulated tungsten microelectrode (impedance, 2$3 \mathrm{M} \Omega$, Kation Scientific, LLC, Minneapolis, MN) was inserted stereotaxically into the left barrel cortex (3 mm lateral and $1.5 \mathrm{~mm}$ caudal to bregma; depth of $0.6 \mathrm{~mm}$ ) through the ACSF-perfused open cranial window for recording local field potentials. An Ag/ $\mathrm{AgCl}$ electrode inserted into the neck muscles served as reference electrode. Changes in cerebral blood flow (CBF) were assessed above the left barrel cortex using a laser Doppler probe (Transonic Systems Inc., Ithaca, NY) as described (Tarantini et al. 2015; Toth et al. 2014; Ungvari et al. 2017a).

After basal activity was recorded, the right whisker pad was stimulated by a bipolar stimulating electrode placed to the ramus infraorbitalis of the trigeminal nerve and into the masticatory muscles. The stimulation protocol used to investigate neurovascular coupling and somatosensory-evoked field potentials consisted of 10 stimulation presentation trials with an intertrial interval of $70 \mathrm{~s}$, each delivering a 30 -s train of electrical pulses ( 2 $\mathrm{Hz}, 0.2 \mathrm{~mA}$, intensity, and $0.3 \mathrm{~ms}$ pulse width) to the mystacial pad after a 10 -s prestimulation baseline period. 
Changes in $\mathrm{CBF}$ were averaged and expressed as percent (\%) increase from the baseline value (Kazama et al. 2004). The electrical signal was amplified with an AC/ DC differential amplifier (high pass at $1 \mathrm{~Hz}$, low pass at $1 \mathrm{kHz}$ ) (Model 3000, A-M Systems, Inc. Carlsborg, WA) and digitalized by the PowerLab/Labchart data acquisition system (ADInstruments, Colorado Springs, CO) with the sampling rate of $40 \mathrm{kHz}$. Analyses were performed on the average of 10 stimulation trials. The negative amplitude in the somatosensory-evoked field potential response was considered as the excitatory postsynaptic potential (fEPSP) (Lind et al. 2013). Experiments lasted $\sim 20-30 \mathrm{~min}$ per mouse, which permitted stable physiological parameters to be obtained. The experimenter was blinded to the treatment of the animals.

Statistical analysis

Statistical analysis was carried out by unpaired or paired $t$ test, as appropriate, using Prism 5.0 for Windows (Graphpad Software, La Jolla, CA). A $p$ value less than 0.05 was considered statistically significant. Data are expressed as mean \pm S.E.M.

\section{Results}

Pharmacologically induced neurovascular uncoupling

Changes in $\mathrm{CBF}$ in the whisker barrel cortex in response to contralateral whisker stimulation were significantly

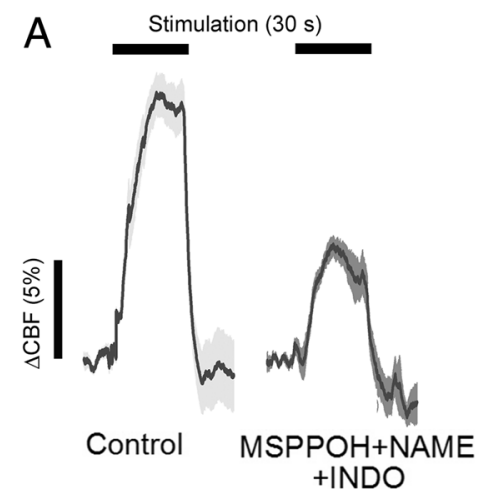

Fig. 1 Pharmacologically induced neurovascular uncoupling in mice. a Time course of cerebral blood flow (CBF) responses measured with a laser Doppler probe above the whisker barrel cortex during electrical stimulation of the contralateral whisker pad (current $0.2 \mathrm{~mA}$, pulse duration $0.3 \mathrm{~ms}$, at $2 \mathrm{~Hz}$ for a $30-\mathrm{s}$ period) obtained in control mice and mice treated chronically with MSPPOH, L-NAME, plus indomethacin (INDO). Shaded areas decreased by in vivo treatment with MSPPOH+ NAME+INDO (Fig. 1a) (Park et al. 2007). Pharmacological treatments could potentially attenuate CBF responses by impairing neural activity evoked by whisker pad stimulation. To examine this possibility, we assessed the effects of treatment with MSPPOH+ NAME+INDO by recording spontaneous and evoked neural activity. We found that the somatosensory field potentials produced by activation of the whisker pad do not differ between control and MSPPOH+NAME+INDO-treated mice (Fig. 1b). Therefore, treatment with MSPPOH+NAME+INDO is unlikely to contribute to impaired functional hyperemia by modulating the neural activity evoked by whisker stimulation (Tarantini et al. 2015). The blood pressure of the two groups of animals did not differ significantly (data not shown).

Effects of neurovascular uncoupling on gait coordination

Gait coordination is a higher integrative process of the sensorimotor system. Clinical studies suggest that neurovascular coupling may be involved in preservation of gait function in elderly people (Sorond et al. 2011). With advanced age, balance and gait speed are reduced (Abellan van Kan et al. 2009; Atkinson et al. 2007; Callisaya et al. 2015; Fitzpatrick et al. 2007; Liu et al. 2017; Nadkarni et al. 2014; Sorond et al. 2010, 2011; Verlinden et al. 2013; Watson et al. 2010), while many other mobility parameters remain unchanged in humans.

$\mathrm{B}$
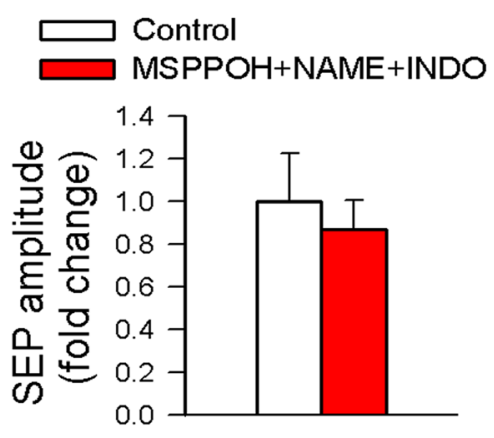

denote $95 \%$ confidence intervals. b Bar graphs showing the effect of treatment with MSPPOH+NAME+INDO on somatosensoryevoked potential (SEP) responses in the primary somatosensory cortex in response to electrical stimulation of the contralateral whisker pad in control and treated groups. The amplitudes of the negative waves were unaffected by chronic treatment of the mice with MSPPOH+NAME+INDO. Data are mean $\pm \mathrm{SEM}$ 
In the present study, we did not observe differences between control mice and mice treated with MSPPOH+ NAME+INDO in the following parameters indicative of gait: speed (Fig. 2a), swing speed (Fig. 2b), cadence (Fig. 2c), stride length (Fig. 2d), stride time (Fig. 2e), base of support (front paws; Fig. 2g), base of support (hind paws; Fig. 2h), and terminal dual stance (Fig. 2i). Pharmacologically induced neurovascular uncoupling significantly decreased the dynamic gait parameter duty cycle, which represents stance duration as a percentage of step cycle duration (Fig. 2f).

The regularity index tended to decrease in mice treated with MSPPOH+NAME+INDO (Fig. 3a). Mice in both groups predominantly used the four most common footfall patterns (Fig. 3b). The primary differences in patterns used by control mice and mice with pharmacologically induced neurovascular uncoupling were in the frequency of the radial "giraffe walk" AA pattern. Mice with neurovascular uncoupling used more frequently the AA pattern than control mice, and compensated with a decreased use of the alternating $A B$ pattern and $\mathrm{CB}$ pattern.

Interlimb coordination was also analyzed by phase dispersion analysis. Mean homologous, ipsilateral, and diagonal phase dispersion values, obtained in animals studied at comparable walking speeds, were calculated for the respective limb pairs and their deviations from the expected phase dispersion values were computed. As shown in Fig. 3c, significantly higher phase dispersion was evident in mice treated with MSPPOH+NAME+INDO as compared to controls.
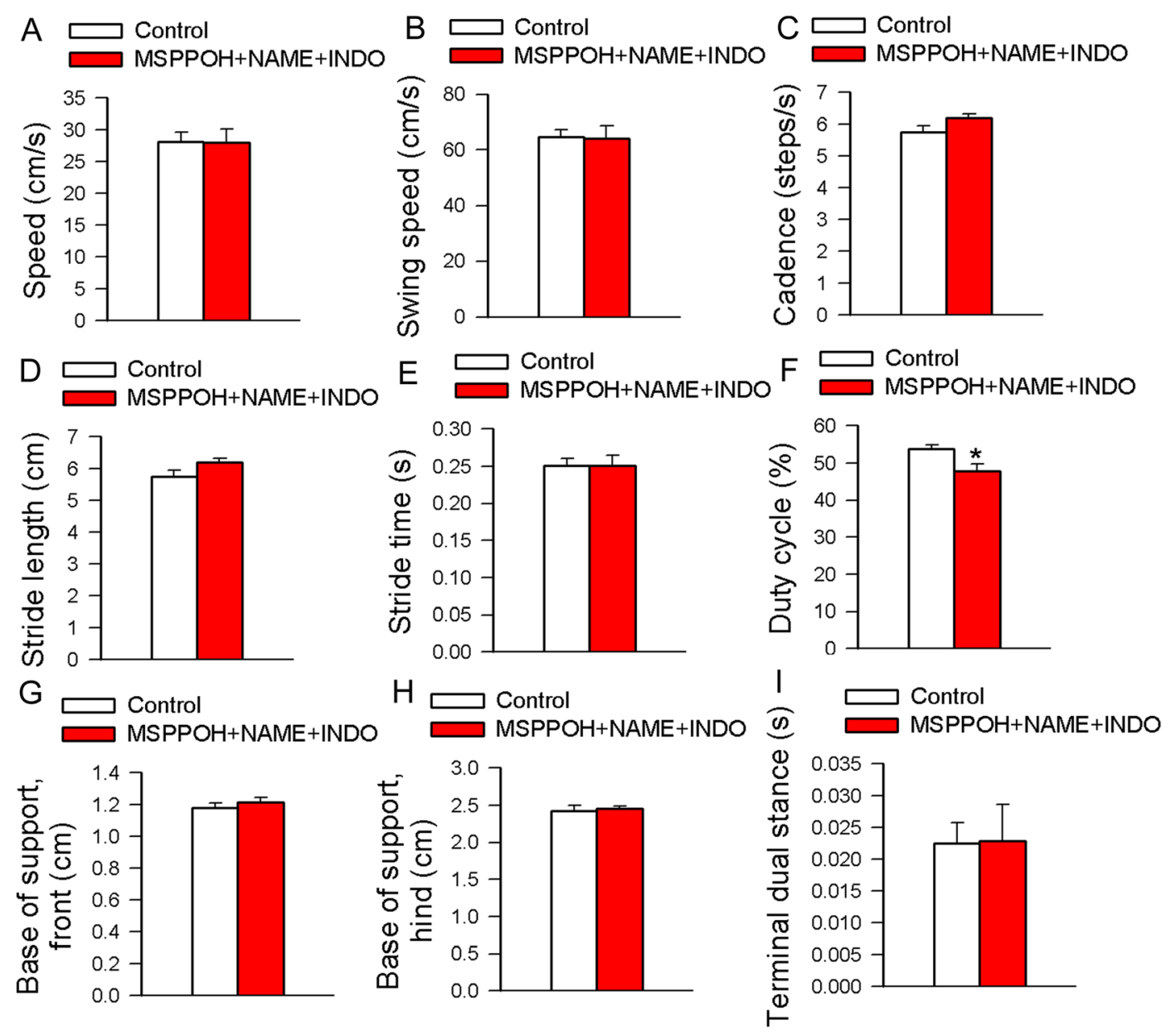

Fig. 2 Effects of neurovascular uncoupling on gait parameters. a Body speed, b swing speed, c cadence, $\mathbf{d}$ stride length, e stride time, $\mathbf{f}$ duty cycle, $\mathbf{g}$ and $\mathbf{h}$ base of support ( $\mathbf{g}$ front paws; $\mathbf{h}$ hind paws), and $\mathbf{i}$ terminal dual stance in control mice and mice treated chronically with MSPPOH, L-NAME, plus indomethacin (INDO). Data are mean $\pm \operatorname{SEM}$ ( $n=10$ in each group). $* P<0.05$ vs. control 

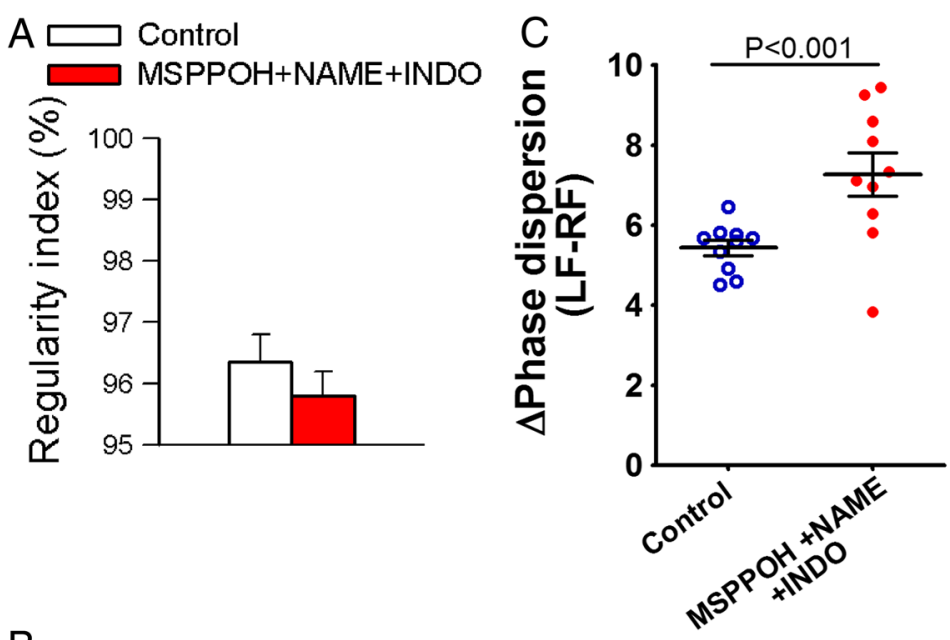

B

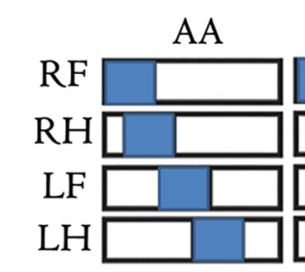

$\mathrm{AB}$

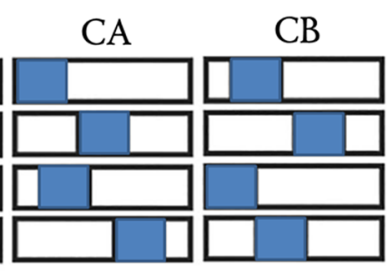

MSPPOH+NAME

Control: $28 \%$

+INDO: $33 \%$

$21 \%$

$19 \%$

$33 \%$

$17 \%$

Fig. 3 Neurovascular uncoupling impairs gait coordination. a A similar sequence regularity index reflects no change in step patterns in mice treated with MSPPOH+NAME+INDO as compared to control mice. b Hildebrand plot of the common gait patterns: AA (RF-RH-LF-LH), AB (LF-RH-RF-LH), CA (RF-LF-RHLH), and CB (LF-RF-LH-RH). Percentages indicate relative use of each step pattern in each mouse group. The most common step pattern in both was the CA pattern. Mice with neurovascular

The study of gait variability, the stride-to-stride fluctuations in walking first observed by von Vierordt (1881), offers a sensitive method of quantifying locomotion. Previous studies demonstrated that measures of gait variability may be more closely related to cognitive decline or falls than other measures based on the mean values of other gait parameters. Stride length variability is in fact a strong predictor of falls and cognitive impairment in elderly patients (Montero-Odasso et al. 2014; Nakamura et al. 1996; Rosso et al. 2014; Studenski et al. 2011; Verghese et al. 2007, 2008, 2009; Verlinden et al. 2013; Visser, 1983; Wittwer et al. 2013). We found that in mice treated with MSPPOH+NAME+INDO there was a discernable trend for increased stride length variability (Fig. 4a) and stride time variability (Fig. 4b).

\section{Discussion}

The present study provides evidence that neurovascular uncoupling is associated with changes in mouse gait coordination. This is complementary to previous data demonstrating that pharmacologically induced neurovascular uncoupling in mice also promotes detectable cognitive impairment (Tarantini et al. 2015).

Gait and balance disorders are ubiquitous in aging. In addition to being a major cause of falls, they are also associated with increased morbidity and mortality, as well as reduced level of function and increased risk of institutionalization. Clinically diagnosed gait abnormalities in older adults involve multiple contributing factors, including neurological diseases (e.g., strokes, Parkinson's disease) (Hajjar et al. 2009). Clinical 

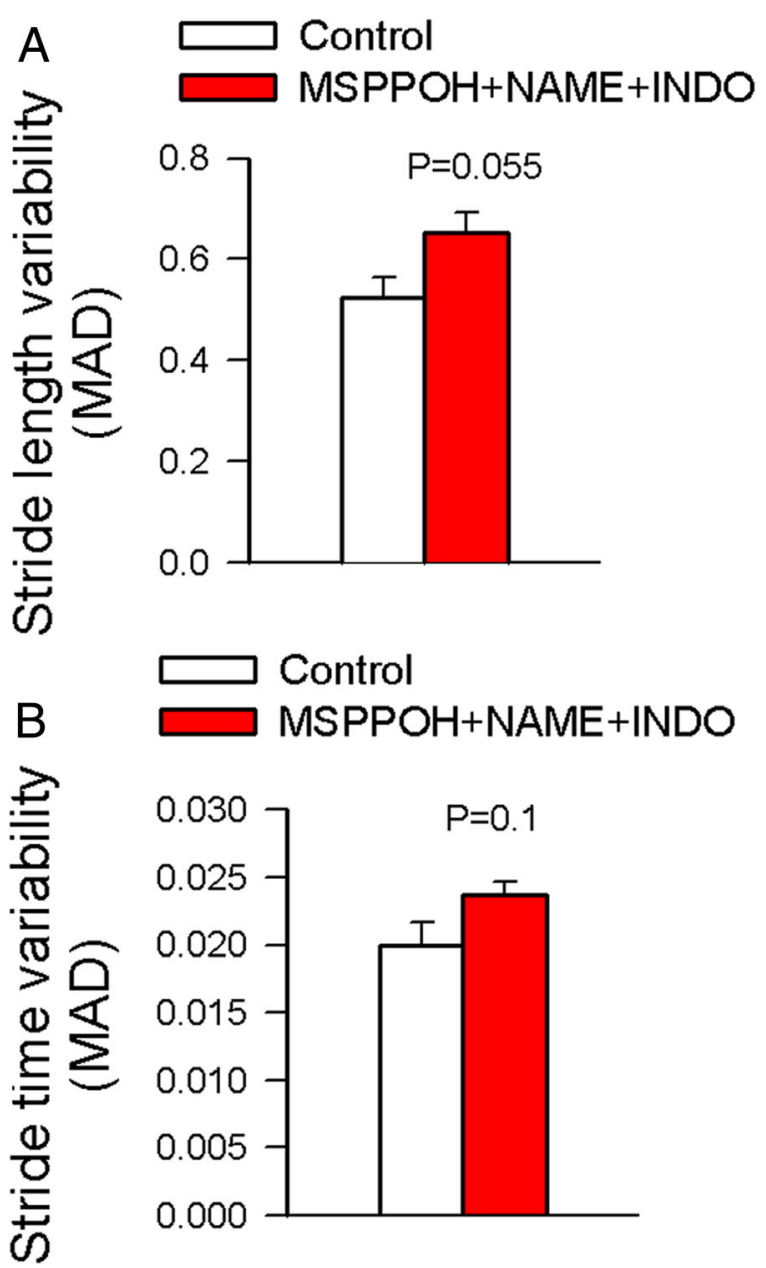

Fig. 4 Neurovascular uncoupling tends to increase gait variability. a Stride length variability and $\mathbf{b}$ stride time variability in spontaneously walking control mice and mice treated chronically with MSPPOH, L-NAME, plus indomethacin (INDO). Data are mean $\pm \operatorname{SEM}(n=10$ in each group). MAD median absolute deviation

studies, including the MOBILIZE Boston study (Sorond et al. 2011), link neurovascular uncoupling to subtle gait dysfunction (e.g., slowing of gait) in humans. Recent studies extend these findings, demonstrating that neurovascular coupling, assessed using transcranial Doppler, is related to activation of brain regions within the executive network, which predicts gait alterations in older adults (Jor'dan et al. 2017). While these findings regarding the association between neurovascular uncoupling and gait abnormalities were intriguing, a cause-and-effect relationship cannot be established given the cross-sectional nature of these studies. In the present study, short-term experimentally induced isolated neurovascular uncoupling resulted in significant change in duty cycle, phase dispersion, and gait pattern, whereas no significant changes in gait speed, cadence, base of support, stride length, and stride time. These findings provide direct evidence that a cause-and-effect relationship likely exists between impairment of neurovascular coupling responses and alteration in gait coordination, supporting the conclusions of earlier clinical studies (Sorond et al. 2011). Our results also warrant further studies on different modalities of gait (e.g., indices reflecting gait coordination) in the context of neurovascular uncoupling in humans. There are several lines of evidence in support of the concept that induction of neurovascular uncoupling is the main mechanism by which inhibition of synthesis of EETs, prostaglandins, and NO affects brain function (Leithner et al. 2010; Tarantini et al. 2015). Although we cannot exclude the possibility that the inhibition of synthesis of nitric oxide, prostaglandins, and EETs may also affect other aspects of neural, glial, or vascular mechanisms, which were not investigated in this study, it did not affect somatosensoryevoked potentials in the barrel cortex (Tarantini et al. 2015). Previous investigations also did not observe alterations in basic synaptic transmission parameters and observed normal long-term potentiation response of fEPSPs in the hippocampus using inhibitors of synthesis of nitric oxide, EETs, and prostaglandins (Leithner et al. 2010; Tarantini et al. 2015).

Healthy neural control systems can fine tune the stride-to-stride fluctuations of gait. Gait variability is a sensitive parameter, which in older humans was reported to predict cognitive decline (Brach et al. 2008; Callisaya et al. 2010; Cedervall et al. 2014; Decker et al. 2016; Gillain et al. 2016; Herman et al. 2005; Verghese et al. 2002, 2007, 2008; Wittwer et al. 2013) and survival(Verlinden et al. 2013) and associated with risk of falls (Verghese et al. 2010). There is strong evidence that vascular pathologies promote gait variability. For example, subclinical brain vascular abnormalities, measured on brain MRIs as infarcts and white matter hyperintensities, were reported to associate with greater variability of spatial gait parameters (step length) (Rosano et al. 2007). In older adults, gait variability is thought to be associated with areas important for sensorimotor integration, coordination (Tian et al. 2017), and memory and executive function (Rosso et al. 2014). In the present study, there was a discernible trend for increased gait variability after induction of neurovascular uncoupling. It will be interesting to determine whether a similar relationship exists 
between gait variability and neurovascular uncoupling in older humans. If this is the case, then it could be proposed that even subclinical impairment of neurovascular function in aging may exacerbate the complex gait abnormalities in older patients. In that regard, it is important to point out that in aging, and age-related pathophysiological conditions (e.g., hypertension), neurovascular uncoupling often co-occurs with other microvascular pathophysiological alterations (e.g., microhemorrhages (Ungvari et al. 2017b), white matter hyperintensities (Sorond et al. 2013)), which are also known to cause gait abnormalities (Toth et al. 2015c). It should be thus emphasized that specific patterns of gait variability may imply different underlying causes (Brach et al. 2008).

Our findings have important clinical relevance. Experimentally induced neurovascular uncoupling mimics impairment of functional hyperemia observed in aging (Toth et al. 2014) and pathophysiological conditions associated with accelerated cerebromicrovascular aging. Advanced age promotes neurovascular uncoupling, at least in part, by decreasing NO bioavailability (Park et al. 2007; Tarantini et al. 2016; Toth et al. 2014). A wide range of pathophysiological conditions in the elderly was shown to adversely affect the synthesis and/or release of NO and astrocyte-derived vasoactive eicosanoid mediators, promoting neurovascular uncoupling (Girouard and Iadecola 2006; Kazama et al. 2004; Tucsek et al. 2014). Cardiovascular risk factors, including hypertension (Kazama et al. 2003, 2004), dyslipidemia, smoking, low circulating IGF1 levels (Toth et al. 2015a), and obesity (Tucsek et al. 2014b), which are all important risk factors for cognitive decline in elderly patients (Gorelick et al. 2011; Iadecola et al. 2009; Miralbell et al. 2013), also inhibit NO mediation of neurovascular coupling and microvascular dilations by promoting oxidative stress, uncoupling endothelial NO synthase and/or by upregulating asymmetric dimethylarginine (ADMA), an endogenous inhibitor of NO synthase. In that regard, it is important that a significant association between serum ADMA level and slower gait speed was demonstrated among elderly individuals (Obayashi et al. 2016). Type 2 diabetes mellitus (Duarte et al. 2015) also leads to neurovascular dysfunction, which is associated with increased risk for brain function loss and long-term cognitive impairment (Biessels and Reijmer 2014; Brundel et al. 2012, 2014; de Bresser et al. 2010; Palta et al. 2014; Reijmer et al. 2011; Ruis et al. 2009; Ryan et al. 2014, 2016; van den Berg et al. 2008, 2009, 2010). Increased oxidative stress and heightened inflammation associated with cardiovascular risk factors may also affect arachidonic acid metabolism, decreasing production of vasodilator prostaglandins and EETs and/or increasing synthesis of vasoconstrictor eicosanoids, such as 20-hydroxyeicosatetraenoic acid (20-HETE), contributing to neurovascular dysfunction.

In recent years in gait research, there has been a substantial increase in the use of methodologies that dynamically assess cerebral blood flow during walking. Methods such as functional near-infrared spectroscopy (fNIRS) can be used to assess functional hyperemia through monitoring of blood oxygenation and blood volume in the cortex during neuronal activation, which are profoundly affected by age-related alterations in cerebrovascular hemodynamics. Thus, using these methodologies, the link between impaired functional hyperemia and gait alterations can be elucidated.

On the basis of our present and previous (Tarantini et al. 2015) findings, we posit that pharmacological and non-pharmacological interventions that promote microvascular health and improve neurovascular coupling responses may exert beneficial effects on higher cortical function (Sorond et al. 2013). Recent findings provide initial support for this concept showing that pharmacological or dietary interventions (e.g., treatment with resveratrol in mouse models (Toth et al. 2014; Witte et al. 2014), consumption of cocoa in elderly patients (Sorond et al. 2013)) that rescue endothelial function and neurovascular coupling can improve cognitive function in aging. Further, our recent studies also demonstrate that rescue of neurovascular coupling responses by treatment with the mitochondria-targeted antioxidative compound SS-31 improves gait coordination in aged mice (Tarantini and Ungvari, under review). Second, pharmacological treatments and dietary and lifestyle factors that impair neurovascular coupling (e.g., by inhibiting the synthesis of nitric oxide, epoxyeicosatrienoic acids, and/or prostaglandins) may adversely affect gait coordination and/or cognitive function. For example, pharmacological inhibitors of the synthesis of vasodilator eicosanoids, including indomethacin, were shown to impair neurovascular coupling in humans (Bruhn et al. 2001; Szabo et al. 2014), decreasing BOLD cerebral MRI contrast by over $50 \%$. The available data from the Baltimore Longitudinal Study on Aging also suggest that use of the cyclooxygenase inhibitor aspirin is associated with greater prospective cognitive decline (Waldstein et al. 2010); however, its effect on gait function was not investigated. 
In that regard, the results of the Aspirin in Reducing Events in the Elderly (ASPREE) trial (a placebocontrolled trial of aspirin treatment that will determine the effects of 5 years of daily $100 \mathrm{mg}$ aspirin on gait function in the elderly (McNeil et al. 2017)) will be informative.

Collectively, combined inhibition of production of nitric oxide, epoxyeicosatrienoic acids, and prostanoids significantly reduces $\mathrm{CBF}$ responses to neuronal activation in mice, which mimics neurovascular uncoupling observed in aging and pathophysiological conditions associated with accelerated cerebromicrovascular aging. The results of this study provide experimental evidence in support of the concept that neurovascular uncoupling per se promotes subclinical gait abnormalities. Our findings, taken together with the results of earlier studies (Hamel et al. 2016; Ongali et al. 2014; Papadopoulos et al. 2017; Tong et al. 2012), point to potential benefits of pharmacological and nonpharmacological (e.g., dietary (Sorond et al. 2013)) interventions targeting neurovascular coupling pathways and promoting microvascular health to preserve gait function in aging.

Acknowledgements The authors acknowledge that this work was supported by grants from the American Heart Association (ST, ZU and AC), the Oklahoma Center for the Advancement of Science and Technology (to AC, AY, ZU), the National Center for Complementary and Alternative Medicine (R01-AT006526 to ZU), the National Institute on Aging (R01-AG055395, R01AG047879; R01-AG038747; R01-AG055395), the National Institute of Neurological Disorders and Stroke (NINDS; R01NS100782, R01-NS056218), the Oklahoma Shared Clinical and Translational Resources (OSCTR) program funded by the National Institute of General Medical Sciences (U54GM104938, to AY), the Presbyterian Health Foundation (to ZU, AC, AY), the EUfunded Hungarian grant EFOP-3.6.1-16-2016-00008, and from the NIA-funded Geroscience Training Program in Oklahoma (T32AG052363).

Compliance with ethical standards All the performed procedures were approved by the Institutional Animal Care and Use Committee of the University of Oklahoma Health Sciences Center.

\section{References}

Abellan van Kan G, Rolland Y, Andrieu S, Bauer J, Beauchet O, Bonnefoy $M$ et al (2009) Gait speed at usual pace as a predictor of adverse outcomes in community-dwelling older people an International Academy on Nutrition and Aging (IANA) task force. J Nutr Health Aging 13(10):881-889. https://doi.org/10.1007/s12603-009-0246-z

Atkinson HH, Rosano C, Simonsick EM, Williamson JD, Davis C, Ambrosius WT, Rapp SR, Cesari M, Newman AB, Harris
TB, Rubin SM, Yaffe K, Satterfield S, Kritchevsky SB, for the Health ABC study (2007) Cognitive function, gait speed decline, and comorbidities: the health, aging and body composition study. J Gerontol A Biol Sci Med Sci 62(8):844850. https://doi.org/10.1093/gerona/62.8.844

Attwell D, Buchan AM, Charpak S, Lauritzen M, Macvicar BA, Newman EA (2010) Glial and neuronal control of brain blood flow. Nature 468(7321):232-243. https://doi. org/10.1038/nature09613

Balbi M, Ghosh M, Longden TA, Jativa Vega M, Gesierich B, Hellal F et al (2015) Dysfunction of mouse cerebral arteries during early aging. J Cereb Blood Flow Metab 35(9):14451453. https://doi.org/10.1038/jcbfm.2015.107

Beauchet O, Launay CP, Sekhon H, Barthelemy JC, Roche F, Chabot J, Levinoff EJ, Allali G (2017) Association of increased gait variability while dual tasking and cognitive decline: results from a prospective longitudinal cohort pilot study. Geroscience 39(4):439-445. https://doi. org/10.1007/s11357-017-9992-8

Belghali M, Chastan N, Cignetti F, Davenne D, Decker LM (2017) Loss of gait control assessed by cognitive-motor dual-tasks: pros and cons in detecting people at risk of developing Alzheimer's and Parkinson's diseases. Geroscience 39(3): 305-329. https://doi.org/10.1007/s11357-017-9977-7

Biessels GJ, Reijmer YD (2014) Brain changes underlying cognitive dysfunction in diabetes: what can we learn from MRI? Diabetes 63(7):2244-2252. https://doi.org/10.2337/db140348

Brach JS, Studenski S, Perera S, VanSwearingen JM, Newman AB (2008) Stance time and step width variability have unique contributing impairments in older persons. Gait Posture 27(3):431-439. https://doi.org/10.1016/j.gaitpost.2007.05.016

Brand-Schieber E, Falck JF, Schwartzman M (2000) Selective inhibition of arachidonic acid epoxidation in vivo. J Physiol Pharmacol 51(4 Pt 1):655-672

Bruhn H, Fransson P, Frahm J (2001) Modulation of cerebral blood oxygenation by indomethacin: MRI at rest and functional brain activation. J Magn Reson Imaging 13(3):325334. https://doi.org/10.1002/jmri.1047

Brundel M, van den Berg E, Reijmer YD, de Bresser J, Kappelle LJ, Biessels GJ (2012) Cerebral haemodynamics, cognition and brain volumes in patients with type 2 diabetes. J Diabetes Complicat 26(3):205-209. https://doi.org/10.1016/j. jdiacomp.2012.03.021

Brundel M, Reijmer YD, van Veluw SJ, Kuijf HJ, Luijten PR, Kappelle LJ, Biessels GJ, on behalf of the Utrecht Vascular Cognitive Impairment (VCI) Study Group (2014) Cerebral microvascular lesions on high-resolution 7-Tesla MRI in patients with type 2 diabetes. Diabetes 63(10):3523-3529. https://doi.org/10.2337/db14-0122

Callisaya ML, Blizzard L, Schmidt MD, McGinley JL, Srikanth VK (2010) Ageing and gait variability - a population-based study of older people. Age Ageing 39(2):191-197. https://doi.org/10.1093/ageing/afp250

Callisaya ML, Beare R, Phan T, Blizzard L, Thrift AG, Chen J, Srikanth VK (2015) Progression of white matter hyperintensities of presumed vascular origin increases the risk of falls in older people. J Gerontol A Biol Sci Med Sci 70(3):360-366. https://doi.org/10.1093/gerona/glu148

Callisaya ML, Launay CP, Srikanth VK, Verghese J, Allali G, Beauchet $O$ (2017) Cognitive status, fast walking speed and 
walking speed reserve - the Gait and Alzheimer Interactions Tracking (GAIT) study. Geroscience 39(2):231-239. https://oi.org/10.1007/s11357-017-9973-y

Cedervall Y, Halvorsen K, Aberg AC (2014) A longitudinal study of gait function and characteristics of gait disturbance in individuals with Alzheimer's disease. Gait Posture 39(4): 1022-1027. https://doi.org/10.1016/j.gaitpost.2013.12.026

Chen BR, Kozberg MG, Bouchard MB, Shaik MA, Hillman EM (2014) A critical role for the vascular endothelium in functional neurovascular coupling in the brain. J Am Heart Assoc 3(3):e000787. https://doi.org/10.1161/JAHA.114.000787

Corriveau RA, Bosetti F, Emr M, Gladman JT, Koenig JI, Moy CS, Pahigiannis K, Waddy SP, Koroshetz W (2016) The science of vascular contributions to cognitive impairment and dementia (VCID): a framework for advancing research priorities in the cerebrovascular biology of cognitive decline. Cell Mol Neurobiol 36(2):281-288. https://doi.org/10.1007/s10571-0160334-7

Csiszar A, Tarantini S, Fulop GA, Kiss T, Valcarcel-Ares MN, Galvan V et al (2017) Hypertension impairs neurovascular coupling and promotes microvascular injury: role in exacerbation of Alzheimer's disease. Geroscience 39(4):359-372. https://doi.org/10.1007/s11357-017-9991-9

de Bresser J, Reijmer YD, van den Berg E, Breedijk MA, Kappelle LJ, Viergever MA, Biessels GJ, Utrecht Diabetic Encephalopathy Study Group (2010) Microvascular determinants of cognitive decline and brain volume change in elderly patients with type 2 diabetes. Dement Geriatr Cogn Disord 30(5):381-386. https://doi.org/10.1159/000321354

Decker LM, Cignetti F, Hunt N, Potter JF, Stergiou N, Studenski SA (2016) Effects of aging on the relationship between cognitive demand and step variability during dual-task walking. Age (Dordr) 38(4):363-375. https://doi.org/10.1007 /s11357-016-9941-y

Duarte JV, Pereira JM, Quendera B, Raimundo M, Moreno C, Gomes L et al (2015) Early disrupted neurovascular coupling and changed event level hemodynamic response function in type 2 diabetes: an fMRI study. J Cereb Blood Flow Metab 35(10):1671-1680. https://doi.org/10.1038/jcbfm.2015.106

Fitzpatrick AL, Buchanan CK, Nahin RL, Dekosky ST, Atkinson HH, Carlson MC et al (2007) Associations of gait speed and other measures of physical function with cognition in a healthy cohort of elderly persons. J Gerontol A Biol Sci Med Sci 62(11):1244-1251. https://doi. org/10.1093/gerona/62.11.1244

Gillain S, Drame M, Lekeu F, Wojtasik V, Ricour C, Croisier JL et al (2016) Gait speed or gait variability, which one to use as a marker of risk to develop Alzheimer disease? A pilot study. Aging Clin Exp Res 28(2):249-255. https://doi.org/10.1007 /s40520-015-0392-6

Girouard H, Iadecola C (2006) Neurovascular coupling in the normal brain and in hypertension, stroke, and Alzheimer disease. J Appl Physiol 100(1):328-335. https://doi. org/10.1152/japplphysiol.00966.2005

Gorelick PB, Scuteri A, Black SE, Decarli C, Greenberg SM, Iadecola $C$ et al (2011) Vascular contributions to cognitive impairment and dementia: a statement for healthcare professionals from the American Heart Association/American Stroke Association. Stroke 42(9):2672-2713. https://doi. org/10.1161/STR.0b013e3182299496
Hajjar I, Yang F, Sorond F, Jones RN, Milberg W, Cupples LA, Lipsitz LA (2009) A novel aging phenotype of slow gait, impaired executive function, and depressive symptoms: relationship to blood pressure and other cardiovascular risks. J Gerontol A Biol Sci Med Sci 64(9):994-1001. https://doi. org/10.1093/gerona/glp075

Hamel E, Royea J, Ongali B, Tong XK (2016) Neurovascular and cognitive failure in Alzheimer's disease: benefits of cardiovascular therapy. Cell Mol Neurobiol 36(2):219-232. https://doi.org/10.1007/s10571-015-0285-4

Herman T, Giladi N, Gurevich T, Hausdorff JM (2005) Gait instability and fractal dynamics of older adults with a "cautious" gait: why do certain older adults walk fearfully? Gait Posture 21(2):178-185. https://doi.org/10.1016/j. gaitpost.2004.01.014

Holtzer R, Verghese J, Xue X, Lipton RB (2006) Cognitive processes related to gait velocity: results from the Einstein Aging Study. Neuropsychology 20(2):215-223. https://doi. org/10.1037/0894-4105.20.2.215

Iadecola C, Park L, Capone C (2009) Threats to the mind: aging, amyloid, and hypertension. Stroke 40(3 Suppl):S40-S44. https://doi.org/10.1161/STROKEAHA.108.533638

Jor'dan AJ, Poole VN, Iloputaife I, Milberg W, Manor B, Esterman $\mathrm{M}$ et al (2017) Executive network activation is linked to walking speed in older adults: functional MRI and TCD ultrasound evidence from the MOBILIZE Boston study. J Gerontol A Biol Sci Med Sci 72(12):1669-1675. https://doi. org/10.1093/gerona/glx063

Kazama K, Wang G, Frys K, Anrather J, Iadecola C (2003) Angiotensin II attenuates functional hyperemia in the mouse somatosensory cortex. Am J Physiol Heart Circ Physiol 285(5):H1890-H1899. https://doi. org/10.1152/ajpheart.00464.2003

Kazama K, Anrather J, Zhou P, Girouard H, Frys K, Milner TA, Iadecola C (2004) Angiotensin II impairs neurovascular coupling in neocortex through NADPH oxidase-derived radicals. Circ Res 95(10):1019-1026. https://doi.org/10.1161/01. RES.0000148637.85595.c5

Leithner C, Royl G, Offenhauser N, Fuchtemeier M, KohlBareis M, Villringer A et al (2010) Pharmacological uncoupling of activation induced increases in CBF and CMRO2. J Cereb Blood Flow Metab 30(2):311-322. https://doi.org/10.1038/jcbfm.2009.211

Lind BL, Brazhe AR, Jessen SB, Tan FC, Lauritzen MJ (2013) Rapid stimulus-evoked astrocyte $\mathrm{Ca} 2+$ elevations and hemodynamic responses in mouse somatosensory cortex in vivo. Proc Natl Acad Sci U S A 110(48):E4678-E4687. https://doi. org/10.1073/pnas.1310065110

Liu X, Bhatt T, Wang S, Yang F, Pai YC (2017) Retention of the "first-trial effect" in gait-slip among community-living older adults. Geroscience 39(1):93-102. https://doi. org/10.1007/s11357-017-9963-0

Lourenco CF, Ledo A, Barbosa RM, Laranjinha J (2017) Neurovascular uncoupling in the triple transgenic model of Alzheimer's disease: impaired cerebral blood flow response to neuronal-derived nitric oxide signaling. Exp Neurol 291: 36-43. https://doi.org/10.1016/j.expneurol.2017.01.013

Ma J, Ayata C, Huang PL, Fishman MC, Moskowitz MA (1996) Regional cerebral blood flow response to vibrissal stimulation in mice lacking type I NOS gene expression. Am J Phys 270(3 Pt 2):H1085-H1090 
McNeil JJ, Woods RL, Nelson MR, Murray AM, Reid CM, Kirpach B, Storey E, Shah RC, Wolfe RS, Tonkin AM, Newman AB, Williamson JD, Lockery JE, Margolis KL, Ernst ME, Abhayaratna WP, Stocks N, Fitzgerald SM, Trevaks RE, Orchard SG, Beilin LJ, Donnan GA, Gibbs P, Johnston CI, Grimm RH (2017) Baseline characteristics of participants in the ASPREE (Aspirin in Reducing Events in the Elderly) study. J Gerontol A Biol Sci Med Sci. https://doi. org/10.1093/gerona/glw342

Mielke MM, Roberts RO, Savica R, Cha R, Drubach DI, Christianson T, Pankratz VS, Geda YE, Machulda MM, Ivnik RJ, Knopman DS, Boeve BF, Rocca WA, Petersen RC (2013) Assessing the temporal relationship between cognition and gait: slow gait predicts cognitive decline in the Mayo Clinic Study of Aging. J Gerontol A Biol Sci Med Sci 68(8):929-937. https://doi.org/10.1093/gerona/gls256

Mignardot JB, Deschamps T, Barrey E, Auvinet B, Berrut G, Cornu $\mathrm{C}$ et al (2014) Gait disturbances as specific predictive markers of the first fall onset in elderly people: a two-year prospective observational study. Front Aging Neurosci 6:22

Miralbell J, Lopez-Cancio E, Lopez-Oloriz J, Arenillas JF, Barrios $\mathrm{M}$, Soriano-Raya JJ et al (2013) Cognitive patterns in relation to biomarkers of cerebrovascular disease and vascular risk factors. Cerebrovasc Dis 36(2):98-105. https://doi. org/10.1159/000352059

Montero-Odasso M, Oteng-Amoako A, Speechley M, Gopaul K, Beauchet O, Annweiler C, Muir-Hunter SW (2014) The motor signature of mild cognitive impairment: results from the gait and brain study. J Gerontol A Biol Sci Med Sci 69(11):1415-1421. https://doi.org/10.1093/gerona/glu155

Nadkarni NK, Nunley KA, Aizenstein H, Harris TB, Yaffe K, Satterfield S, Newman AB, Rosano C, for the Health ABC Study (2014) Association between cerebellar gray matter volumes, gait speed, and information-processing ability in older adults enrolled in the Health ABC study. J Gerontol A Biol Sci Med Sci 69(8):996-1003. https://doi.org/10.1093 /gerona/glt151

Nakamura T, Meguro K, Sasaki H (1996) Relationship between falls and stride length variability in senile dementia of the Alzheimer type. Gerontology 42(2):108-113. https://doi. org/10.1159/000213780

Obayashi K, Saeki K, Maegawa T, Sakai T, Kitagawa M, Otaki N, Kataoka H, Kurumatani N (2016) Association of serum asymmetric dimethylarginine with muscle strength and gait speed: a cross-sectional study of the HEIJOKYO cohort. J Bone Miner Res 31(5):1107-1113. https://doi.org/10.1002/jbmr.2773

Ongali B, Nicolakakis N, Tong XK, Aboulkassim T, Papadopoulos P, Rosa-Neto P, Lecrux C, Imboden H, Hamel E (2014) Angiotensin II type 1 receptor blocker losartan prevents and rescues cerebrovascular, neuropathological and cognitive deficits in an Alzheimer's disease model. Neurobiol Dis 68:126-136. https://doi.org/10.1016/j. nbd.2014.04.018

Palta P, Schneider AL, Biessels GJ, Touradji P, Hill-Briggs F (2014) Magnitude of cognitive dysfunction in adults with type 2 diabetes: a meta-analysis of six cognitive domains and the most frequently reported neuropsychological tests within domains. J Int Neuropsychol Soc 20(3):278-291. https://doi.org/10.1017/S1355617713001483
Papadopoulos P, Tong XK, Imboden H, Hamel E (2017) Losartan improves cerebrovascular function in a mouse model of Alzheimer's disease with combined overproduction of amyloid-beta and transforming growth factor-beta1. J Cereb Blood Flow Metab 37(6):1959-1970. https://doi.org/10.1177 /0271678X16658489

Park L, Anrather J, Girouard H, Zhou P, Iadecola C (2007) Nox2derived reactive oxygen species mediate neurovascular dysregulation in the aging mouse brain. J Cereb Blood Flow Metab 27(12):1908-1918. https://doi.org/10.1038/sj. jcbfm.9600491

Peng X, Carhuapoma JR, Bhardwaj A, Alkayed NJ, Falck JR, Harder DR, Traystman RJ, Koehler RC (2002) Suppression of cortical functional hyperemia to vibrissal stimulation in the rat by epoxygenase inhibitors. Am J Physiol Heart Circ Physiol 283(5):H2029-H2037. https://doi.org/10.1152/ajpheart.01130.2000

Reijmer YD, van den Berg E, de Bresser J, Kessels RP, Kappelle LJ, Algra A et al (2011) Accelerated cognitive decline in patients with type 2 diabetes: MRI correlates and risk factors. Diabetes Metab Res Rev 27(2):195-202. https://doi. org/10.1002/dmrr.1163

Rosano C, Brach J, Studenski S, Longstreth WT Jr, Newman AB (2007) Gait variability is associated with subclinical brain vascular abnormalities in high-functioning older adults. Neuroepidemiology 29(3-4):193-200. https://doi. org/10.1159/000111582

Rosso AL, Olson Hunt MJ, Yang M, Brach JS, Harris TB, Newman AB, Satterfield S, Studenski SA, Yaffe K, Aizenstein HJ, Rosano C, Health ABC study (2014) Higher step length variability indicates lower gray matter integrity of selected regions in older adults. Gait Posture 40(1):225-230. https://doi.org/10.1016/j.gaitpost.2014.03.192

Ruis C, Biessels GJ, Gorter KJ, van den Donk M, Kappelle LJ, Rutten GE (2009) Cognition in the early stage of type 2 diabetes. Diabetes Care 32(7):1261-1265. https://doi. org/10.2337/dc08-2143

Ryan JP, Fine DF, Rosano C (2014) Type 2 diabetes and cognitive impairment: contributions from neuroimaging. J Geriatr Psychiatry Neurol 27(1):47-55. https://doi.org/10.1177 /0891988713516543

Ryan CM, van Duinkerken E, Rosano C (2016) Neurocognitive consequences of diabetes. Am Psychol 71(7):563-576. https://doi.org/10.1037/a0040455

Snyder HM, Corriveau RA, Craft S, Faber JE, Greenberg SM, Knopman D, Lamb BT, Montine TJ, Nedergaard M, Schaffer CB, Schneider JA, Wellington C, Wilcock DM, Zipfel GJ, Zlokovic B, Bain LJ, Bosetti F, Galis ZS, Koroshetz W, Carrillo MC (2015) Vascular contributions to cognitive impairment and dementia including Alzheimer's disease. Alzheimers Dement 11(6): 710-717. https://doi.org/10.1016/j.jalz.2014.10.008

Sorond FA, Galica A, Serrador JM, Kiely DK, Iloputaife I, Cupples LA, Lipsitz LA (2010) Cerebrovascular hemodynamics, gait, and falls in an elderly population: MOBILIZE Boston study. Neurology 74(20):1627-1633. https://doi. org/10.1212/WNL.0b013e3181df0982

Sorond FA, Kiely DK, Galica A, Moscufo N, Serrador JM, Iloputaife I, Egorova S, Dell'Oglio E, Meier DS, Newton E, Milberg WP, Guttmann CRG, Lipsitz 1 (2011) Neurovascular coupling is impaired in slow walkers: 
the MOBILIZE Boston study. Ann Neurol 70(2):213220. https://doi.org/10.1002/ana.22433

Sorond FA, Hurwitz S, Salat DH, Greve DN, Fisher ND (2013) Neurovascular coupling, cerebral white matter integrity, and response to cocoa in older people. Neurology 81(10):904909. https://doi.org/10.1212/WNL.0b013e3182a351aa

Stefanova I, Stephan T, Becker-Bense S, Dera T, Brandt T, Dieterich M (2013) Age-related changes of blood-oxygenlevel-dependent signal dynamics during optokinetic stimulation. Neurobiol Aging 34(10):2277-2286. https://doi. org/10.1016/j.neurobiolaging.2013.03.031

Stobart JL, Lu L, Anderson HD, Mori H, Anderson CM (2013) Astrocyte-induced cortical vasodilation is mediated by Dserine and endothelial nitric oxide synthase. Proc Natl Acad Sci U S A 110(8):3149-3154. https://doi. org/10.1073/pnas. 1215929110

Studenski S, Perera S, Patel K, Rosano C, Faulkner K, Inzitari M, Brach J, Chandler J, Cawthon P, Connor EB, Nevitt M, Visser M, Kritchevsky S, Badinelli S, Harris T, Newman AB, Cauley J, Ferrucci L, Guralnik J (2011) Gait speed and survival in older adults. JAMA 305(1):50-58. https://doi. org/10.1001/jama.2010.1923

Szabo K, Rosengarten B, Juhasz T, Lako E, Csiba L, Olah L (2014) Effect of non-steroid anti-inflammatory drugs on neurovascular coupling in humans. J Neurol Sci 336(1-2): 227-231. https://doi.org/10.1016/j.jns.2013.10.048

Takano T, Tian GF, Peng W, Lou N, Libionka W, Han X, Nedergaard M (2006) Astrocyte-mediated control of cerebral blood flow. Nat Neurosci 9(2):260-267. https://doi. org $10.1038 / \mathrm{nn} 1623$

Tarantini S, Hertelendy P, Tucsek Z, Valcarcel-Ares MN, Smith N, Menyhart A, Farkas E, Hodges EL, Towner R, Deak F, Sonntag WE, Csiszar A, Ungvari Z, Toth P (2015) Pharmacologically-induced neurovascular uncoupling is associated with cognitive impairment in mice. J Cereb Blood Flow Metab 35(11):1871-1881. https://doi.org/10.1038/jcbfm.2015.162

Tarantini S, Tran CH, Gordon GR, Ungvari Z, Csiszar A (2016) Impaired neurovascular coupling in aging and Alzheimer's disease: contribution of astrocyte dysfunction and endothelial impairment to cognitive decline. Exp Gerontol. https://doi. org/10.1016/j.exger.2016.1011.1004

Tarantini S, Fulop GA, Kiss T, Farkas E, Zolei-Szenasi D, Galvan $\mathrm{V}$ et al (2017) Demonstration of impaired neurovascular coupling responses in TG2576 mouse model of Alzheimer's disease using functional laser speckle contrast imaging. Geroscience 39(4):465-473. https://doi. org/10.1007/s11357-017-9980-z

Tian Q, Chastan N, Bair WN, Resnick SM, Ferrucci L, Studenski SA (2017) The brain map of gait variability in aging, cognitive impairment and dementia - a systematic review. Neurosci Biobehav Rev 74(Pt A):149-162

Tong XK, Lecrux C, Rosa-Neto P, Hamel E (2012) Agedependent rescue by simvastatin of Alzheimer's disease cerebrovascular and memory deficits. J Neurosci 32(14):47054715. https://doi.org/10.1523/JNEUROSCI.0169-12.2012

Topcuoglu MA, Aydin H, Saka E (2009) Occipital cortex activation studied with simultaneous recordings of functional transcranial Doppler ultrasound (fTCD) and visual evoked potential (VEP) in cognitively normal human subjects: effect of healthy aging. Neurosci Lett 452(1):17-22. https://doi. org/10.1016/j.neulet.2009.01.030

Toth P, Tucsek Z, Sosnowska D, Gautam T, Mitschelen M, Tarantini S, Deak F, Koller A, Sonntag WE, Csiszar A, Ungvari Z (2013) Age-related autoregulatory dysfunction and cerebromicrovascular injury in mice with angiotensin II-induced hypertension. J Cereb Blood Flow Metab 33(11):1732-1742. https://doi.org/10.1038/jcbfm.2013.143

Toth P, Tarantini S, Tucsek Z, Ashpole NM, Sosnowska D, Gautam T, Ballabh P, Koller A, Sonntag WE, Csiszar A, Ungvari Z (2014) Resveratrol treatment rescues neurovascular coupling in aged mice: role of improved cerebromicrovascular endothelial function and downregulation of NADPH oxidase. Am J Physiol Heart Circ Physiol 306(3):H299-H308. https://doi. org/10.1152/ajpheart.00744.2013

Toth P, Tarantini S, Ashpole NM, Tucsek Z, Milne GL, Valcarcel-Ares NM, Menyhart A, Farkas E, Sonntag WE, Csiszar A, Ungvari Z (2015a) IGF-1 deficiency impairs neurovascular coupling in mice: implications for cerebromicrovascular aging. Aging Cell 14(6): 1034-1044. https://doi.org/10.1111/acel.12372

Toth P, Tarantini S, Davila A, Valcarcel-Ares MN, Tucsek Z, Varamini B, Ballabh P, Sonntag WE, Baur JA, Csiszar A, Ungvari Z (2015b) Purinergic glio-endothelial coupling during neuronal activity: role of $\mathrm{P} 2 \mathrm{Y} 1$ receptors and eNOS in functional hyperemia in the mouse somatosensory cortex. Am J Physiol Heart Circ Physiol 309(11):H1837-H1845. https://doi.org/10.1152/ajpheart.00463.2015

Toth P, Tarantini S, Springo Z, Tucsek Z, Gautam T, Giles CB, Wren JD, Koller A, Sonntag WE, Csiszar A, Ungvari Z (2015c) Aging exacerbates hypertension-induced cerebral microhemorrhages in mice: role of resveratrol treatment in vasoprotection. Aging Cell 14(3):400-408. https://doi. org/10.1111/acel.12315

Toth P, Tarantini S, Csiszar A, Ungvari Z (2017) Functional vascular contributions to cognitive impairment and dementia: mechanisms and consequences of cerebral autoregulatory dysfunction, endothelial impairment, and neurovascular uncoupling in aging. Am J Physiol Heart Circ Physiol 312(1):H1-H20. https://doi.org/10.1152/ajpheart.00581.2016

Tucsek Z, Toth P, Sosnowska D, Gautam T, Mitschelen M, Koller A, et al (2014) Obesity in aging exacerbates blood-brain barrier disruption, neuroinflammation, and oxidative stress in the mouse hippocampus: effects on expression of genes involved in beta-amyloid generation and Alzheimer's disease. J Gerontol A Biol Sci Med Sci 69(11):1339-1352. https://doi.org/10.1093/gerona/glu080

Tucsek Z, Toth P, Sosnowska D, Gautam T, Mitschelen M, Koller A, Szalai G, Sonntag WE, Ungvari Z, Csiszar A (2014a) Obesity in aging exacerbates blood-brain barrier disruption, neuroinflammation, and oxidative stress in the mouse hippocampus: effects on expression of genes involved in beta-amyloid generation and Alzheimer's disease. J Gerontol A Biol Sci Med Sci 69(10):1212-1226. https://doi.org/10.1093/gerona/glt177

Tucsek Z, Toth P, Tarantini S, Sosnowska D, Gautam T, Warrington JP, Giles CB, Wren JD, Koller A, Ballabh P, Sonntag WE, Ungvari Z, Csiszar A (2014b) Aging exacerbates obesity-induced cerebromicrovascular rarefaction, neurovascular uncoupling, and cognitive decline in mice. J 
Gerontol A Biol Sci Med Sci 69(11):1339-1352. https://doi. org/10.1093/gerona/glu080

Tucsek Z, Noa Valcarcel-Ares M, Tarantini S, Yabluchanskiy A, Fulop G, Gautam T et al (2017) Hypertension-induced synapse loss and impairment in synaptic plasticity in the mouse hippocampus mimics the aging phenotype: implications for the pathogenesis of vascular cognitive impairment. Geroscience 39(4):385-406. https://doi.org/10.1007/s11357-017-9981-y

Ungvari Z, Tarantini S, Hertelendy P, Valcarcel-Ares MN, Fulop GA, Logan S et al (2017a) Cerebromicrovascular dysfunction predicts cognitive decline and gait abnormalities in a mouse model of whole brain irradiation-induced accelerated brain senescence. Geroscience 39(1):33-42. https://doi. org/10.1007/s11357-017-9964-Z

Ungvari Z, Tarantini S, Kirkpatrick AC, Csiszar A, Prodan CI (2017b) Cerebral microhemorrhages: mechanisms, consequences, and prevention. Am J Physiol Heart Circ Physiol 312(6):H1128-H1143. https://doi. org/10.1152/ajpheart.00780.2016

van den Berg E, Dekker JM, Nijpels G, Kessels RP, Kappelle LJ, de Haan EH et al (2008) Cognitive functioning in elderly persons with type 2 diabetes and metabolic syndrome: the Hoorn study. Dement Geriatr Cogn Disord 26(3):261-269. https://doi.org/10.1159/000160959

van den Berg E, Kloppenborg RP, Kessels RP, Kappelle LJ, Biessels GJ (2009) Type 2 diabetes mellitus, hypertension, dyslipidemia and obesity: a systematic comparison of their impact on cognition. Biochim Biophys Acta 1792(5):470481. https://doi.org/10.1016/j.bbadis.2008.09.004

van den Berg E, Reijmer YD, de Bresser J, Kessels RP, Kappelle LJ, Biessels GJ (2010) A 4 year follow-up study of cognitive functioning in patients with type 2 diabetes mellitus. Diabetologia 53(1):58-65. https://doi.org/10.1007/s00125009-1571-9

Verghese J, Lipton RB, Hall CB, Kuslansky G, Katz MJ, Buschke $\mathrm{H}$ (2002) Abnormality of gait as a predictor of nonAlzheimer's dementia. N Engl J Med 347(22):1761-1768. https://doi.org/10.1056/NEJMoa020441

Verghese J, Wang C, Lipton RB, Holtzer R, Xue X (2007) Quantitative gait dysfunction and risk of cognitive decline and dementia. J Neurol Neurosurg Psychiatry 78(9):929935. https://doi.org/10.1136/jnnp.2006.106914

Verghese J, Robbins M, Holtzer R, Zimmerman M, Wang C, Xue X, Lipton RB (2008) Gait dysfunction in mild cognitive impairment syndromes. J Am Geriatr Soc 56(7):12441251. https://doi.org/10.1111/j.1532-5415.2008.01758.x

Verghese J, Holtzer R, Lipton RB, Wang C (2009) Quantitative gait markers and incident fall risk in older adults. J Gerontol A Biol Sci Med Sci 64(8):896-901. https://doi.org/10.1093/gerona/glp033
Verghese J, Ambrose AF, Lipton RB, Wang C (2010) Neurological gait abnormalities and risk of falls in older adults. J Neurol 257(3):392-398. https://doi. org/10.1007/s00415-009-5332-y

Verlinden VJ, van der Geest JN, Hoogendam YY, Hofman A, Breteler MM, Ikram MA (2013) Gait patterns in a community-dwelling population aged 50 years and older. Gait Posture 37(4):500-505. https://doi.org/10.1016/j. gaitpost.2012.09.005

Visser H (1983) Gait and balance in senile dementia of Alzheimer's type. Age Ageing 12(4):296-301. https://doi. org/10.1093/ageing/12.4.296

von Vierordt K (1881) Über das Gehen des Menschen in Gesunden und Kranken Zustaenden nach Selbstregistrireden Methoden, (On human gait in health and disease using a self-recording method) edn. Laupp, Tuebigen, Germany

Wakisaka Y, Chu Y, Miller JD, Rosenberg GA, Heistad DD (2010) Spontaneous intracerebral hemorrhage during acute and chronic hypertension in mice. J Cereb Blood Flow Metab 30(1):56-69. https://doi.org/10.1038/jcbfm.2009.183

Waldstein SR, Wendell CR, Seliger SL, Ferrucci L, Metter EJ, Zonderman AB (2010) Nonsteroidal anti-inflammatory drugs, aspirin, and cognitive function in the Baltimore longitudinal study of aging. J Am Geriatr Soc 58(1):38-43. https://doi.org/10.1111/j.1532-5415.2009.02618.x

Watson NL, Rosano C, Boudreau RM, Simonsick EM, Ferrucci L, Sutton-Tyrrell K, Hardy SE, Atkinson HH, Yaffe K, Satterfield S, Harris TB, Newman AB, Health ABC Study (2010) Executive function, memory, and gait speed decline in well-functioning older adults. J Gerontol A Biol Sci Med Sci 65(10):1093-1100. https://doi.org/10.1093/gerona/glq111

Witte AV, Kerti L, Margulies DS, Floel A (2014) Effects of resveratrol on memory performance, hippocampal functional connectivity, and glucose metabolism in healthy older adults. J Neurosci 34(23):7862-7870. https://doi. org/10.1523/JNEUROSCI.0385-14.2014

Wittwer JE, Webster KE, Hill K (2013) Reproducibility of gait variability measures in people with Alzheimer's disease. Gait Posture 38(3):507-510. https://doi.org/10.1016/j. gaitpost.2013.01.021

Zlokovic BV (2011) Neurovascular pathways to neurodegeneration in Alzheimer's disease and other disorders. Nat Rev Neurosci 12(12):723-738. https://doi.org/10.1038/nrn3114

Zonta M, Angulo MC, Gobbo S, Rosengarten B, Hossmann KA, Pozzan T, Carmignoto G (2003) Neuron-to-astrocyte signaling is central to the dynamic control of brain microcirculation. Nat Neurosci 6(1):43-50. https://doi. org/10.1038/nn980 